DOI 10. 18307/2021. 0504

(C) 2021 by Journal of Lake Sciences

\title{
湖泊水体微生物四醚膜脂化合物研究进展
}

\author{
李婧婧 ${ }^{* * *}$,杨 欢 $^{2}$, 郑峰峰 ${ }^{3}$, 高 超 ${ }^{2}$, 雷丽丹 ${ }^{4}$ \\ (1: 中国科学院南京地理与湖泊研究所湖泊与环境国家重点实验室,南京 210008) \\ (2: 中国地质大学 (武汉) 生物地质与环境地质国家重点实验室流域关键带演化湖北省重点实验室, 武汉 430074) \\ (3:南方科技大学海洋科学与工程系深圳古菌组学重点实验室,深圳 518055) \\ (4:西南大学岩溶环境重庆市重点实验室,重庆 400715)
}

摘 要: 来源于微生物膜脂的甘油二烷基甘油四醚类 (GDGTs) 化合物是近年来被广泛用于古环境定量重建研究的化合 物之一, 究其原因在于此类化合物对环境响应敏感, 特别是温度与 $\mathrm{pH}$ 值等, 据此而建立的一系列 GDGTs 指标有效定量重 建海洋、湖泊、泥炭以及土壤等不同沉积载体的环境信息. 目前已在全球范围广泛开展湖泊沉积物 GDGTs 的研究工作, 相 继建立的全球以及不同区域尺度的湖泊沉积物 GDGTs 校正方程, 已被用于湖泊古环境的定量重建研究, 有效记载古湖泊 环境变迁信息. 相较之下, 基于湖泊水体 GDGTs 的调查工作则起步较晚,但越来越多的研究显示, 不同类型湖泊水体普遍 贡献 GDGTs, 然而究竟此类水生来源 GDGTs 是否与陆源以及湖泊沉积物 GDGTs 具有类似的分布, 以及他们对环境因素 的响应如何, 这都为湖泊古温度定量重建研究带来不确定性. 基于此, 本文总结这 10 年来湖泊水体 GDGTs 研究工作的进 展, 首先阐述湖泊水体不同来源(古菌以及细菌) GDGTs 的分布情况, 研究发现水体不同层位 GDGTs 浓度以及各组分之 间存在差异, 并且水深在不同湖泊对 GDGTs 浓度以及各组分相对比例的影响存在差异. 此外还总结湖泊水体中古菌来源 isoGDGTs 以及细菌来源 brGDGTs 的生物来源, 并进一步分析环境因素对不同深度水体 GDGTs 分布的影响, 虽然温度依 然是影响水体中 GDGTs 分布的首要因素之一, 然而湖泊水深、温度以及水体中溶解氧浓度等因素存在着一定的耦合关 系,这些因素往往协同作用于水体 GDGTs, 因此会为评估环境因素对水体 GDGTs 的影响带来难度.

关键词：湖泊水体;古菌;细菌;水深;温度

\section{Occurrence and distribution of glycerol dialkyl glycerol tetraethers in lake water column:} A review*

Li Jingjing ${ }^{1 * *}$, Yang Huan ${ }^{2}$, Zheng Fengfeng ${ }^{3}$, Gao $\mathrm{Chao}^{2} \&$ Lei Lidan ${ }^{4}$

(1: State Key Laboratory of Lake Science and Environment, Nanjing Institute of Geography and Limnology, Chinese Academy of Sciences, Nanjing 210008, P.R.China)

(2: State Key Laboratory of Biogeology and Environmental Geology, Hubei Key Laboratory of Critical Zone Evolution, China University of Geosciences, Wuhan 430074, P.R.China)

(3: Shenzhen Key Laboratory of Marine Archaea Geo-Omics, Department of Ocean Science \& Engineering, Southern University of Science and Technology, Shenzhen 518055, P.R.China)

(4: Chongqing Key Laboratory of Karst Environment, Southwest University, Chongqing 400715, P.R.China)

Abstract: Glycerol dialkyl glycerol tetraethers (GDGT) are membrane lipids that have become a useful tool in palaeoclimatology, the GDGT-based proxies have been applied to reconstruct paleoclimatic variation in marine, lake, peat bog and soils environments due to their sensitivity to environmental parameters, such as temperature and $\mathrm{pH}$. Several calibrations based on the distribution of GDGTs in lake surface sediments have been established in global and regional lakes, they have been widely utilized to reconstructed environmental variation in paleolimnology. Compare to the ubiquitous occurrence of GDGTs in lake sediments, GDGTs analysis

* 2020-10-23 收稿;2020-12-28 收修改稿.

国家自然科学基金项目 (41977384)、江苏省基础研究计划 (自然科学基金) 面上项目 (BK20181508) 和中国地质大 学 (武汉) 生物地质与环境地质国家重点实验室开放基金项目 (GBL21805) 联合资助.

** 通信作者;E-mail:jjli@ niglas.ac.cn. 
of the lake water column is limited, however, increasing evidence has demonstrated that the contribution of GDGTs from the lake water column to lake sediments is not negligible. It is thus vital to address the relationship between the distribution pattern of aquatic origin GDGTs within the lake water column and environmental factors before we apply the GDGT-based proxies in lake environments to reconstruct paleoclimate. In this paper, we first introduced the GDGTs distribution in the lake water column, to see whether there was a correlation between GDGTs distribution and water depth in terms of the GDGT concentration and the fractional abundance of individual GDGTs. We also reviewed the biological source of the archaea derived isoGDGTs and bacteria-derived brGDGTs of the lake water column, respectively. Further, we found that temperature was still one of the main controlling environmental factors that influence the fractional abundance of GDGTs and other related GDGT-based proxies in the lake water column, however, it is worth noting that the coupling relationship between temperature, water depth and dissolved oxygen in the lake could complicate the GDGTs distribution in the water column.

Keywords: Lake water column; archaea; bacteria; water depth; temperature

来源于微生物细胞膜脂的甘油二烷基甘油四梄 ( glycerol dialkyl glycerol tetraethers, GDGTs), 是一类对环 境参数响应敏感的化合物, 特别是温度以及 $\mathrm{pH}$ 值, 因此成为近年来古环境定量重建研究的热点之一 ${ }^{[1]}$. 根 据生物来源、碳链结构以及立体构型等差异,GDGTs 主要分为两种类型,一类是来源于古菌的类异戊二烯 GDGTs (isoprenoid GDGTs, 简称 isoGDGTs), 其碳骨架以类异戊二烯 $\left(-\mathrm{C}_{5} \mathrm{H}_{12}\right)$ 为单元, 并携带不同个数的五 元环和六元环, 甘油构型为 $2,3-$ 二- $O$-酰基- $s n$-甘油结构 (图 1); 另一类则是由细菌合成的支链 GDGTs (branched GDGTs, 简称 brGDGTs), 碳骨架由携带不同个数甲基 $\left(-\mathrm{CH}_{3}\right)$ 的 $\mathrm{C}_{28}$ 烷基链组成, 携带 $0 \sim 2$ 个五 元环, 甘油构型为 1,2 -二- $O$-酰基- $s n$-甘油结构 (图 1 $)^{[2]}$. 近 10 年来, 随着测试技术和分离手段的逐步优化, 有别于传统结构的四醚类化合物也被陆续鉴定,包括碳链上携带不同个数羟基 $(-\mathrm{OH})$ 以及五元环的羟基 $\operatorname{GDGTs}$ ( hydroxy GDGTs, 简称 OH-GDGTs) ${ }^{[3]}$ (图 1)、两条碳链以一个共价键联接的甘油单烷基甘油四醚化 合物 ( glycerol monoalkyl glycerol tetraethers, 简称 GMGT, 因结构形似 H, 也称 H-GDGTs $)^{[4-5]}$. 此外, isoGDGTs 以及 brGDGTs 的异构体 (isomers) 也被有效分离 ${ }^{[6-7]}$, 近年来对不同生境这些化合物的生物来源及其所蕴含 环境信息的研究,已为古环境变迁以及定量重建研究提供了新基础与新方法 ${ }^{[8-10]}$.

GDGTs 与环境参数之间的定量关系也被逐步挖掘, 其中被广泛用于古环境定量重建的 GDGTs 指标主 要有两种, 分别是 $\mathrm{TEX}_{86}$ 与 $\mathrm{MBT} / \mathrm{CBT}$ 指标 ${ }^{[11]}$. $\mathrm{TEX}_{86}$ ( tetraether index of 86 carbon atoms) 指标首先构建于海 洋环境, 研究显示海洋表层沉积物中 isoGDGTs 碳链上五元环的环化程度与海水表层温度 ( sea surface temperature, SST) 之间存在显著正相关关系 ${ }^{[12]}$, 其生理学基础是这些 isoGDGTs 来源于海洋奇古菌 Thaumarchaeota 1.1a, 可以通过改变自身环化程度以适应环境温度变化 ${ }^{[13]}$. MBT/CBT 指标 (methylation index/cyclisation ratio of branched tetraethers) 则是根据土壤细菌合成的 brGDGTs, 其甲基化和环化程度有效 指示大气年均气温 (annual mean air temperature, MAT) 以及 $\mathrm{pH}$ 值的变化 ${ }^{[14]}$. 与海洋和土壤相比, 湖泊在物 理 (大小、深浅、流域形态) 和化学 (温度、盐度、 $\mathrm{pH}$ 值、氧浓度以及营养盐浓度) 等特征上呈现多样性的特点, 然而即使在极端湖泊, 如高盐 ${ }^{[15]}$ 、富/寡营养 ${ }^{[16]}$ 湖泊等也能检测到 GDGTs 的分布, 这为湖泊环境开展 GDGTs 研究提供了重要前提. 事实上, 将上述基于海洋与土壤环境构建的 $\mathrm{TEX}_{86} 、 \mathrm{MBT} / \mathrm{CBT}$ 指标应用到湖泊 环境, 在一定程度上也能定量重建湖泊温度和 $\mathrm{pH}$ 值的变化 ${ }^{[17-19]}$. 然而随着研究工作的逐步推进, 这些指标 在湖泊环境的应用也面临着挑战和不确定性, 因为湖泊沉积物合成有别于土壤的 GDGTs ${ }^{[15,20-21]}$, 因此将基 于土壤环境建立的 MBT/CBT 指标生搬硬套于湖泊环境, 必然会造成恢复的温度或者 $\mathrm{pH}$ 值与实测值之间的 误差, 故后续根据湖泊环境 brGDGTs 分布特征而建立 MBT/CBT 指标 ${ }^{[22-23]}$, 以及选取湖泊 brGDGTs 中对环 境响应最敏感的组分构建逐步回归方程 ${ }^{[24-26]}$, 以此进一步优化 GDGTs 在湖泊古环境定量重建的准确性.

然而越来越多的研究显示, 湖泊水体也会贡献 GDGTs, 并且由于不同湖泊物理、化学以及生物属性的差 异, 不同湖泊水体合成的 GDGTs 存在差异, 以及在同一湖泊水体不同层位的 GDGTs 也存在差异性分布 ${ }^{[27]}$, 表明水体中 GDGTs 分布的多样性, 这是在以往研究中经常被忽略的部分. 例如水体中混人产甲烷古菌与甲 烷氧化古菌的影响 ${ }^{[28-29]}$, 则势必会贡献与对温度响应敏感的奇古菌 Thaumarchaeota 1.1a 类似的 isoGDGTs 分 布模式 ${ }^{[13]}$, 而这些不同来源的 GDGTs 对温度响应存在差异, 因此如果在利用 GDGTs 进行古环境定量重建 时, 对这些不同古菌来源 isoGDGTs 进行无差别计算, 不仅会引起重建温度的偏差, 更是忽略湖泊水体中生 

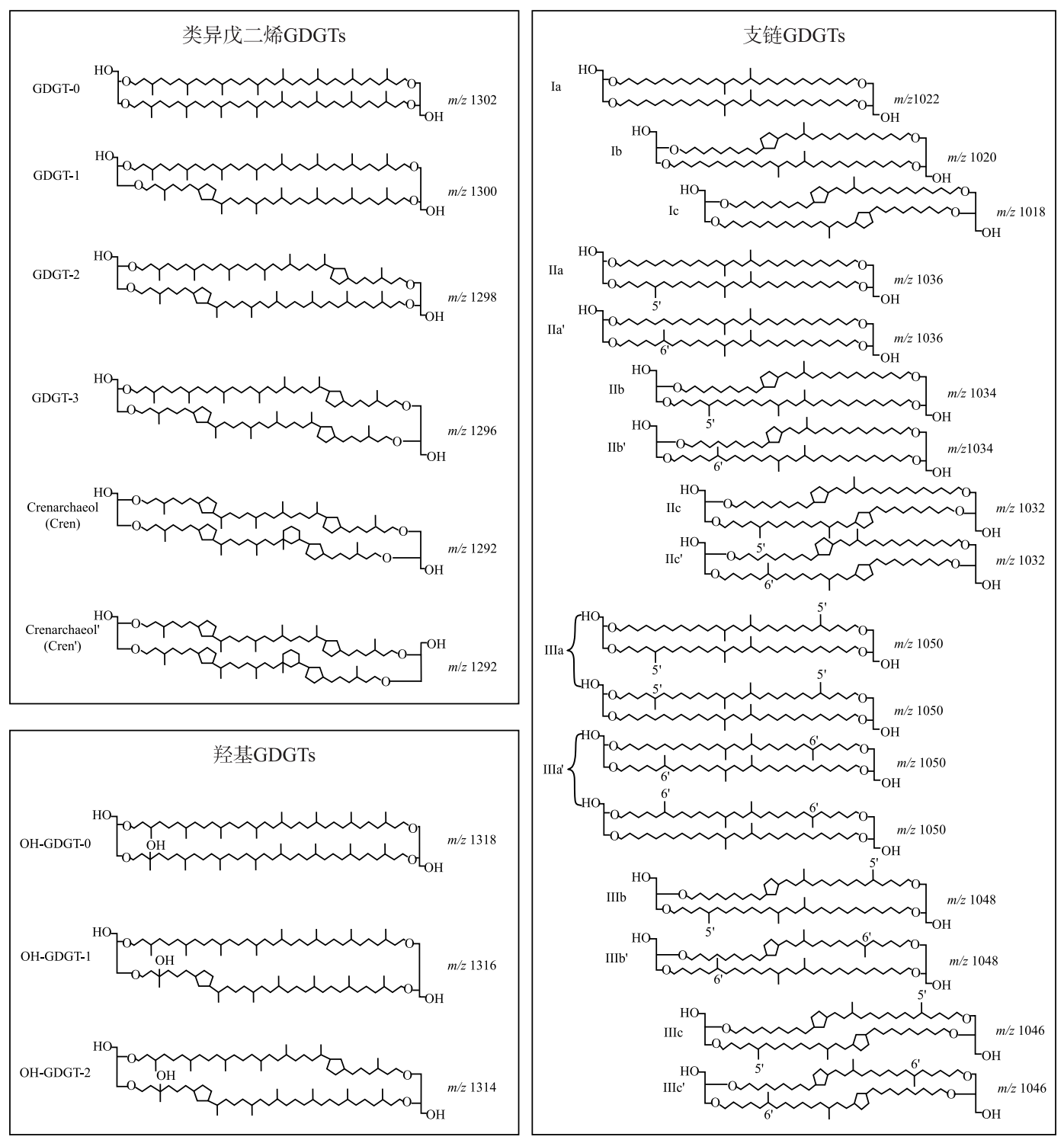

图 1 文中涉及的类异戊二烯 isoGDGTs, 羟基 OH-GDGTs 与支链 brGDGTs 的化学结构

(其中 isoGDGTs 以及 OH-GDGTs 的阿拉伯数字指示五元环个数; brGDGTs 的罗马数字指示甲基个数, 字母指示五元环个数,化合物携带“'”符号则指示 6-甲基 brGDGTs, 即甲基位于碳链的 $\alpha$ 和/或 $\omega$-6 位置)

Fig.1 Chemical structure of isoprenoid GDGTs, hydroxy GDGTs and branched GDGTs discussed in this text

(For isoGDGTs and OH-GDGTs, arabic numbers indicate the cyclopentane rings. For brGDGTs, roman numbers indicate tetra-( I ), penta-( II ), and hexamethylated ( III) brGDGTs, letters indicate the absence (a), presence of one (b), and two (c) cyclopentane rings, while the prime symbols indicate 6-methyl brGDGT isomers in which the additional methyl groups occur at the $\alpha$ and/or $\omega-6$ position instead of $\alpha$ and/or $\omega-5$ position of 5-methyl brGDGTs)

物地球化学过程的研究. 因此即使利用上述基于湖泊沉积物构建的 GDGTs 相关指标来重建环境变迁信息 时,也往往会带来误差. 事实上湖泊水体普遍合成 GDGTs, 这些化合物的生物来源以及对环境响应如何, 是 
否有别于土壤或者湖泊沉积物中的 GDGTs 还需进一步挖掘, 鉴于其普遍性以及对湖泊沉积物 GDGTs 的重 要贡献,非常有必要开展湖泊水体 GDGTs 的现代过程研究.

与 2000 年就在全球范围开展的湖泊沉积物 GDGTs 调查工作相比 ${ }^{[30]}$, 湖泊水体 GDGTs 的研究工作始于 2009 年 ${ }^{[28]}$, 起步较晚且相对分散, 涉及欧洲、非洲、北美以及中国等地区的湖泊 (图 2,3), 主要通过获取水 体悬浮颗粒物 ( suspended particulate matter, SPM) 的方式来富集 GDGTs ${ }^{[28]}$, 或者借助沉积物捕获器 ( sediment trap) 手段来富集水体中的沉降颗粒 (settling particles) 以获取不同时间分辨率的 GDGTs 样品 ${ }^{[27]}$ (表 1). 借助 这两种富集方式已在不同类型湖泊开展水体 GDGTs 研究,包括深/浅水湖泊、富营养/寡营养湖泊以及水深 相对较浅的池塘 (Pond) 等. 就目前研究现状来看, 湖泊水体 GDGTs 研究的关键问题包括以下几个方面: 首 先水体 GDGTs 分布特征如何, 对于深水湖泊不同层位的水体, 其 GDGTs 分布是否存在深度差异, 如果存在, 控制因子是什么; 其次, 湖泊水体 GDGTs 分布是否存在时间差异, 其分布有无季节性效应. 基于以上问题, 本文总结这 10 年来前人在湖泊水体 GDGTs 研究方向的进展, 首先介绍水体 GDGTs 的分布模式及其来源, 并进一步分析影响水体 GDGTs 分布的因素, 为后续准确开展 GDGTs 古环境定量重建研究提供基础和佐证.

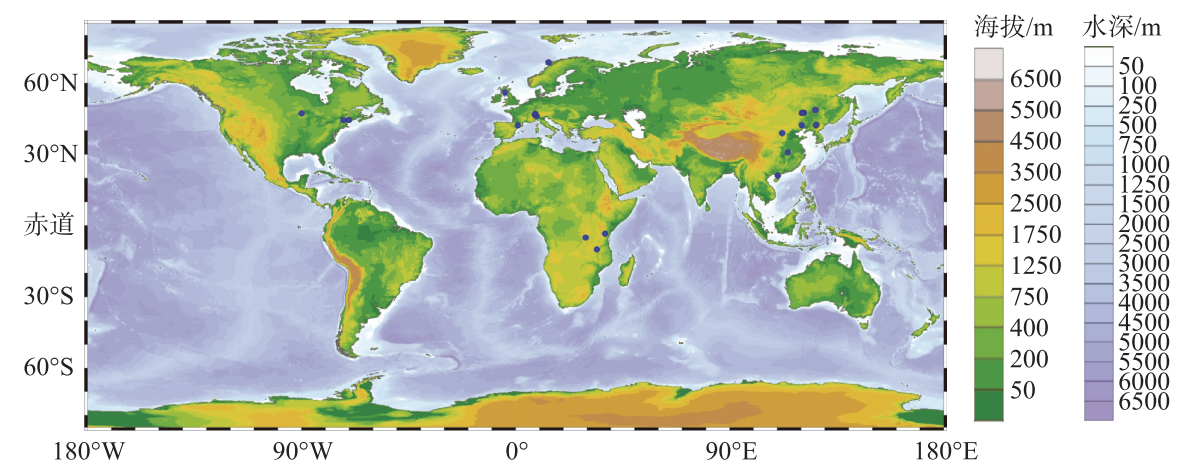

图 2 全球已开展水体 GDGTs 研究的湖泊 (参考文献详见表 1)

Fig.2 Distribution of GDGTs in global lake water column from previous literature, refer to Tab.1

\section{1 湖泊水体 GDGTs 分布研究}

作为一个相对独立的沉积载体,湖泊可以分布在 每一个自然带,不同湖泊在地质、地貌、气候和水文等 自然条件上的差异,导致湖泊水体在物理、化学以及 生物属性上呈现多样性. 特别是在深水湖泊,湖泊水 体因水深、温度以及溶解氧 ( DO ) 等参数的差异, 会产 生比较显著的分层现象,即水体不同层位的差别. 需 要注意的是,虽然 GDGTs 在浅水湖泊也有分布, 然而 在水深相对较浅的湖泊,并不显著的水深差可能无法 引起 GDGTs 的显著性差异分布. 为方便阐述总结这 些湖泊水体 GDGTs 分布特征, 本部分将从不同生物 来源(古菌vs 细菌) GDGTs 浓度与各组分变化这两 个方面,梳理近年来湖泊水体,特别是深水湖泊不同 深度水体 GDGTs 研究进展.

\section{1 湖泊水体 GDGTs 浓度随水深变化研究}

不同类型湖泊的调查结果显示水体不同层位均可合成 GDGTs, 例如即使在非洲深水湖泊一 Tanganyika 湖水深 $1000 \mathrm{~m}$ 处, 也能检测出不同类型 GDGTs 化合物的分布 ${ }^{[31]}$. 然而由于水体不同层位存在温 度、含氧量、光照以及营养盐浓度等因素的差异 ${ }^{[32-34]}$, 在某种程度上影响合成 GDGTs 微生物的生长或繁盛, 
从而导致 GDGTs 浓度在不同层位水体出现差异, 并且不同湖泊水体中 GDGTs 浓度随水深变化的规律也不 尽相同 (表 1), 在某些湖泊呈现显著上升或降低的趋势,在某些湖泊则未呈现显著变化,抑或并非呈线性上 升或者下降的模式. 此外, 考虑到本文对湖泊水柱 GDGTs 浓度的对比研究大多在同一湖泊完成, 因此并没 有比对不同湖泊 GDGTs 浓度研究, 故也未对不同研究中 GDGTs 浓度或者通量做统一数学换算分析.

表 1 不同湖泊水体 isoGDGTs 与 brGDGTs 浓度随水深的变化

Tab.1 Variation of the isoGDGTs and/or brGDGTs concentrations with water depth in water column from different lakes

\begin{tabular}{|c|c|c|c|c|c|c|c|c|}
\hline \multirow{2}{*}{ 湖泊名称 } & \multirow{2}{*}{$\begin{array}{c}\text { 最大水深/ } \\
\mathrm{m}\end{array}$} & \multirow{2}{*}{$\begin{array}{l}\text { 面积/ } \\
\mathrm{km}^{2}\end{array}$} & \multirow{2}{*}{ 类型/特征 } & \multicolumn{2}{|c|}{ 浓度随水深变化 } & \multicolumn{2}{|c|}{ 采样方式 } & \multirow{2}{*}{ 文献 } \\
\hline & & & & isoGDGTs & brGDGTs & Trap & SPM & \\
\hline Chala 湖 & 98 & 4.5 & 火山湖 & 增加 & 增加 & $\checkmark$ & $\checkmark$ & {$[28]$} \\
\hline Brienz 湖 & 260 & 29.8 & 寡营养湖 & 降低 & 降低 & $x$ & $\checkmark$ & {$[16]$} \\
\hline Lugano 湖 & 288 & 4.69 & 富营养湖 & 降低 & 降低 & & & \\
\hline Lucerne 湖 & 104 & 113 & 寡营养湖 & 增加 & 增加 & $\checkmark$ & $\checkmark$ & {$[39]$} \\
\hline Superior 湖 & 406 & 82413 & 塞营养湖 & 增加 & 增加 & $\checkmark$ & $\checkmark$ & {$[40]$} \\
\hline Tanganyika 湖 & 1436 & 32900 & 断陷湖 & 先增后减 & 先增后减 & $x$ & $\checkmark$ & {$[31]$} \\
\hline Challa 湖 & 98 & 4.5 & 火山湖 & $\begin{array}{l}\text { GDGT-0 增加, 其他 } \\
\text { 化合物先增加后降低 }\end{array}$ & - & $x$ & $\checkmark$ & {$[36]$} \\
\hline Rotsee 湖 & 16 & 0.46 & 富营养湖泊 & 降低 & 降低 & $x$ & $\checkmark$ & {$[21]$} \\
\hline Lower King 池塘 & 8 & 0.016 & 碟形湖 & - & $\begin{array}{c}\text { 春季、夏初降低; } \\
\text { 仲夏增加 }\end{array}$ & $\checkmark$ & $\checkmark$ & {$[41]$} \\
\hline Challa 湖 & 98 & 4.5 & 火山湖 & - & 增加 & $\checkmark$ & $\checkmark$ & {$[37]$} \\
\hline Lomond 湖 & 190 & 71 & 单对流湖 & 增加 & 不显著 & $\checkmark$ & $\checkmark$ & {$[42]$} \\
\hline 湖光岩 & 20 & 2.3 & 玛珥湖 & 不显著 & 增加 & $\checkmark$ & $\checkmark$ & {$[34]$} \\
\hline Interpollen 湖 & 44 & - & 沿海湖 & 增加 & 降低 & $x$ & $\checkmark$ & {$[33]$} \\
\hline Lugano 湖 & 288 & 4.69 & 富营养湖 & - & $\begin{array}{c}\text { III a、 III a"增加, } \\
\text { III a' 先增加后降低 }\end{array}$ & $\checkmark$ & $\checkmark$ & {$[32]$} \\
\hline Basin 池塘 & 32.6 & 0.14 & 深水池塘 & - & 增加 & $\checkmark$ & $\checkmark$ & {$[43]$} \\
\hline 东湖 & 6 & 32.5 & 富营养浅水湖 & - & - & $x$ & $\checkmark$ & {$[44]$} \\
\hline Malawi 湖 & 700 & 29604 & 断陷湖 & 先增后减 & - & $x$ & $\checkmark$ & {$[45]$} \\
\hline 火山湖 & $3 \sim 127$ & $0.1 \sim 8.2$ & 火山湖 & 增加 & - & $x$ & $\checkmark$ & {$[46]$} \\
\hline 公海 & 10 & 0.36 & 冬季有冰覆盖 & - & 不显著 & $x$ & $\checkmark$ & {$[47]$} \\
\hline 火山湖 & $3 \sim 127$ & $0.1 \sim 8.2$ & 火山湖 & - & 增加 & $x$ & $\checkmark$ & {$[48]$} \\
\hline Challa 湖 & 98 & 4.5 & 火山湖 & - & 增加 & $\checkmark$ & $\checkmark$ & {$[38]$} \\
\hline Montcortés 湖 & 30 & - & 寡营养湖 & - & 降低 & $\checkmark$ & $\checkmark$ & [49] \\
\hline
\end{tabular}

不同学者在非洲东部赤道附近的火成湖—Chala (也称 Challa) 湖开展了详尽的 GDGTs 研究, 结果显 示该湖泊水体中古菌 isoGDGTs 以及细菌 brGDGTs 的浓度均随水深呈增加趋势, 并在氧跃层附近发生显著 变化, 相较之下, 古菌 isoGDGTs 浓度的增幅要明显高于细菌 brGDGTs ${ }^{[27]}$. 然而这些观测结果是基于 GDGTs 核心脂类 (core lipid, CL) 部分而言, 即微生物死亡并降解之后, 被保存下来的 GDGTs 部分 ${ }^{[35]}$, 为开展对比研 究, 随后有学者分析该湖泊 GDGTs 完整极性 (intact polar lipid, IPL) 脂类部分的变化, 即微生物活体还未降 解,仍携带极性头基部分的 GDGTs ${ }^{[36]}$. 对比结果显示, GDGT-0 与其他 isoGDGTs 化合物呈现并不一致的变 化, 无论是 IPL 还是 CL 部分, GDGT-0 在氧跃层附近均未发生变化, 但在水体深部的厌氧层, 浓度发生显著 增加, 特别是 IPL GDGT-0 的浓度呈数量级增加; 然而除 GDGT-0 以外的其他 isoGDGTs 化合物则是在氧跃层 附近就显著增加, 但在深部戻氧层, 这些 isoGDGTs 的浓度均有所降低, 但仍高于水体上部含氧层位 ${ }^{[36]}$. 随后 在对 Chala 湖不同深度水体 IPL brGDGTs 以及 CL brGDGTs 浓度变化的研究中发现, 虽然两者均呈现随水深 增加的趋势, 但后者的增幅要明显高于前者, 因此在水体深部的戻氧层, 用来指示 IPL 与 CL 相对比例的 
IPL \% 也由水体上层的 35\% 降低至 10\% ${ }^{[37]}$. 最近有学者报道了 Chala 湖 brGDGTs 及其异构体在水体中的变 化研究, 发现几类浓度占优势的 brGDGTs 化合物, 其浓度均随水深增加, 在水体深部的厌氧层达到最高 ${ }^{[38]}$. 综上对非洲 Chala 湖水体 GDGTs 浓度的研究可以发现, 不同类型 GDGTs 化合物随水深变化的表现不尽相 同,但大多随水深呈现增加的趋势.

除非洲 Chala 湖以外, 在其他湖泊水体中也有类似规律, 即 isoGDGTs 与 brGDGTs 的浓度均随水深增加, 如瑞士深水湖泊 Lucerne 湖 ${ }^{[39]}$ 以及北美深水湖泊 Superior 湖 ${ }^{[40]}$. 当然并不是所有湖泊都能够同时满足这两 类 GDGTs 浓度变化的研究,往往侧重某一类 GDGTs 化合物的分析. 例如在不同类型湖泊中也分别观测到 isoGDGTs 以及 brGDGTs 随水深增加的现象, 前者包括东非断陷湖泊 Malawi 湖 ${ }^{[4]}$ 以及中国东北地区火山 湖 $^{[46]}$ 中的 isoGDGTs, 虽然 Malawi 湖的数据表明水体中 isoGDGTs 的浓度随水深增加到一定深度后又呈现下 降趋势; 后者则包括瑞士 Lugano 湖, 研究显示水体中 IPL brGDGTs 以及 CL brGDGTs 浓度均随水深增加, 其 中 IPL brGDGTs 增幅更显著,IPL\% 也由表层水体的 30\% 增至深部水体的 $70 \%{ }^{[32]}$. 此外北美深水池塘 ( Basin 池塘 ${ }^{[43]}$, 以及上述中国东北的火山湖 ${ }^{[48]}$, 水体中 brGDGTs 的浓度也均随水深而呈现增加趋势, 在水体深部 呈现最大值. 需要注意的是, 虽然这些湖泊水体中 isoGDGTs 或者 brGDGTs 的浓度往往呈现随水深增加的现 象, 但不都是简单的线性模式, 在水体最深处这些化合物的浓度也并非达到峰值, 在实际观测中, 往往会发 现 GDGTs 浓度在上升到临界值之后,会呈现下降的趋势.

然而随着研究范围的不断延伸和扩大, 不同深度水体中 GDGTs 浓度随深度增加的现象并非普遍规律, 在不少湖泊均出现下降的趋势, 包括瑞士的富营养湖泊 Lugano 湖以及寡营养湖泊 Brienz 湖, 这两个营养化 程度差异显著的湖泊,无论是在春季还是秋季, 水体中 isoGDGTs 和 brGDGTs 的浓度均随水深而降低 ${ }^{[16]}$. 此 外, 在瑞士的浅水湖泊 Rotsee 湖 ${ }^{[21]}$, 以及地中海附近的一个喀斯特湖也发现类似规律 ${ }^{[49]}$. 当然, 在实际研究 过程中还会发现, 不同深度水体 isoGDGTs 和 brGDGTs 随水深呈现不一致变化的现象, 例如位于中国华南地 区的玛珥湖一一湖光岩, 虽然湖泊最大水深只有 $20 \mathrm{~m}$, 但水体中 brGDGTs 的分布有着显著的 “深度效应”, 深层水体 brGDGTs 的浓度要高于浅层水体, 然而 isoGDGTs 的分布则并未发现类似现象 ${ }^{[34]}$. 同样在挪威的 Indrepollen 湖, 水体中 brGDGTs 和 isoGDGTs 随水深变化的趋势也截然不同, 随着水深的增加, isoGDGTs 浓 度呈现先增加后降低的趋势, 而 brGDGTs 则在表层水体达到峰值, 随后一直保持低浓度但在接近湖底位置 又略有回升 ${ }^{[33]}$. 然而在某些湖泊, 水深对 GDGTs 浓度的影响似乎并不能简单描述为增加或减少, 如北美浅 水碟型池塘 ( Lower King 池塘), 可能是因为水体相对较浅, 因此 brGDGTs 浓度变化较大, 在观测期的绝大多 数时间, 底部水体 brGDGTs 的浓度均要高于表层水体, 然而在观测期的某些时间段, 表层水体 brGDGTs 浓度 会高出底层水体十倍左右 ${ }^{[41]}$.

综上, 在对不同地区、不同类型湖泊水体 GDGTs 浓度与水深关系的研究中不难发现, 虽然大部分湖泊水 体 GDGTs 的浓度随水深发生变化, 呈现增加或者减少的趋势, 并且不同来源 GDGTs 的变化模式还存在差 异. 然而需要注意的是, 在某些湖泊水体 GDGTs 浓度随水深的变化并不显著, 如苏格兰 Lomond 湖以及山西 吕梁山公海, 这两个湖泊水体 GDGTs 浓度似乎并不受水深影响, 与水深之间也不存在显著关系 ${ }^{[42,47]}$, 因此 仅仅考虑 GDGTs 浓度的变化可能还无法全面评估湖泊水体中 GDGTs 的变化, 还需进一步分析水体 GDGTs 各组分的变化规律.

\section{2 湖泊水体 GDGTs 分布特征研究}

GDGTs 组成的差异主要体现在不同类型 GDGTs 化合物的相对浓度以及相对浓度最高的化合物 (最占 优势组分) 的变化上,此外 GDGTs 的相关指标如 $\mathrm{TEX}_{86} 、 \mathrm{MBT} / \mathrm{CBT}$ 等的变化也在一定程度上反映水体 GDGTs 组分变化的信息,据此本部分将分别阐述 isoGDGTs 与 brGDGTs 组成在不同深度水体中的分布特征. 1.2.1 湖泊水体 isoGDGTs 分布特征研究 以开展 GDGTs 系统研究的 Chala 湖为例, 陆续有研究报道 isoGDGTs 各化合物在不同层位水体的变化特征. 其中开展较早的研究工作仅关注 CL isoGDGTs 组分的变 化, 结果显示在氧浓度较高的上层水体, 不携带任何环结构的 GDGT-0 与指示奇古菌的特征标志物—crenarchaeol, 两者的相对浓度差别不大, 但在氧跃层附近均发生显著增加, 特别是在水体深部的缺氧层位, GDGT-0 浓度增加明显, 约高出上层含氧水体两个数量级, 且远高于 crenarchaeol, 虽然后者的浓度随水深也 呈上升趋势 ${ }^{[27]}$. 这与后续分别探讨 CL isoGDGTs 以及 IPL isoGDGTs 的研究结果一致,即表层水体中 CL 
GDGT-0 的浓度占优势, 但在位于水体中部的氧跃层附近, CL crenarchaeol 的浓度显著升高, 成为该层位的主 要组分, 然而随着水深的继续增加, CL crenarchaeol 逐渐降低, 相反 CL GDGT-0 的浓度显著上升, 从而成为 Chala 湖水体深部厌氧层的主要组分 ${ }^{[36]}$. 值得注意的是, GDGT-0 以及 crenarchaeol 作为 Chala 湖水体中浓度 较高的组分, 这两类化合物的 IPL 以及 CL 组分随水深变化并不一致 ${ }^{[36]}$. 来自水体 3 个不同深度即氧跃层以 上、氧跃层以及氧跃层以下的结果显示, IPL GDGT-0 在上层含氧水体以及深部厌氧层位的相对浓度都很高, 占明显优势, 分别占到 $80 \%$ 以及 $90 \%$ 以上, 然而 CL GDGT-0 的相对浓度仅在深部厌氧层位呈现高值, 达到 $90 \%$ 以上; 相反 crenarchaeol 的 IPL 以及 CL 在深部厌氧层位的浓度都很低, 但 CL crenarchaeol 在氧跃层附近 浓度较高, 远高于 CL GDGT-0, 相较之下在此深度, IPL crenarchaeol 与 CL crenarchaeol 相对浓度很接近 ${ }^{[36]}$. 1.2.2 湖泊水体 brGDGTs 分布特征研究 同样是在非洲 Chala 湖开展的工作, 研究初期的结果显示, 不同层 位水体 brGDGTs 均以相对高浓度的 II 占主导, 但 III 的相对浓度则随水深而减少, 而 I 随水深则未发生显著 变化 ${ }^{[27]}$. 最近有学者报道该湖泊不同深度水体 brGDGTs 及其异构体的分布情况 (图 4), 与研究初期未有效 分离 brGDGTs 的结果类似, II 仍然是水体中分布最多的化合物 ${ }^{[38]}$. 但需要注意的是, 新近被分离的 5-甲基 brGDGTs 以及 6-甲基 brGDGTs 异构体, 这两类化合物的浓度在不同的水体分层时期会呈现差异性变化,例 如在观测期的第 1 个水体分层时期 (2013-2014 年), 5-甲基 brGDGTs 系列化合物， I b、 II b 的浓度在水深 35 60 m 处占优势, 而 6-甲基 brGDGTs 系列化合物, II $\mathrm{a}^{\prime}$ 、 III $\mathrm{a}^{\prime}$ 的浓度则在底部水体 (60 80 m 处) 较高; 而 在第 2 个水体分层时期 (2014- 2015 年) , I b、II b 的浓度较第 1 个水体分层时期显著减少, 并且高浓度的 II $\mathrm{a}^{\prime} 、$ III $\mathrm{a}^{\prime}$ 出现在水深 $25 \sim 35 \mathrm{~m}$ 处, 明显有别于第 1 个分层时期的水体底部 ${ }^{[38]}$.
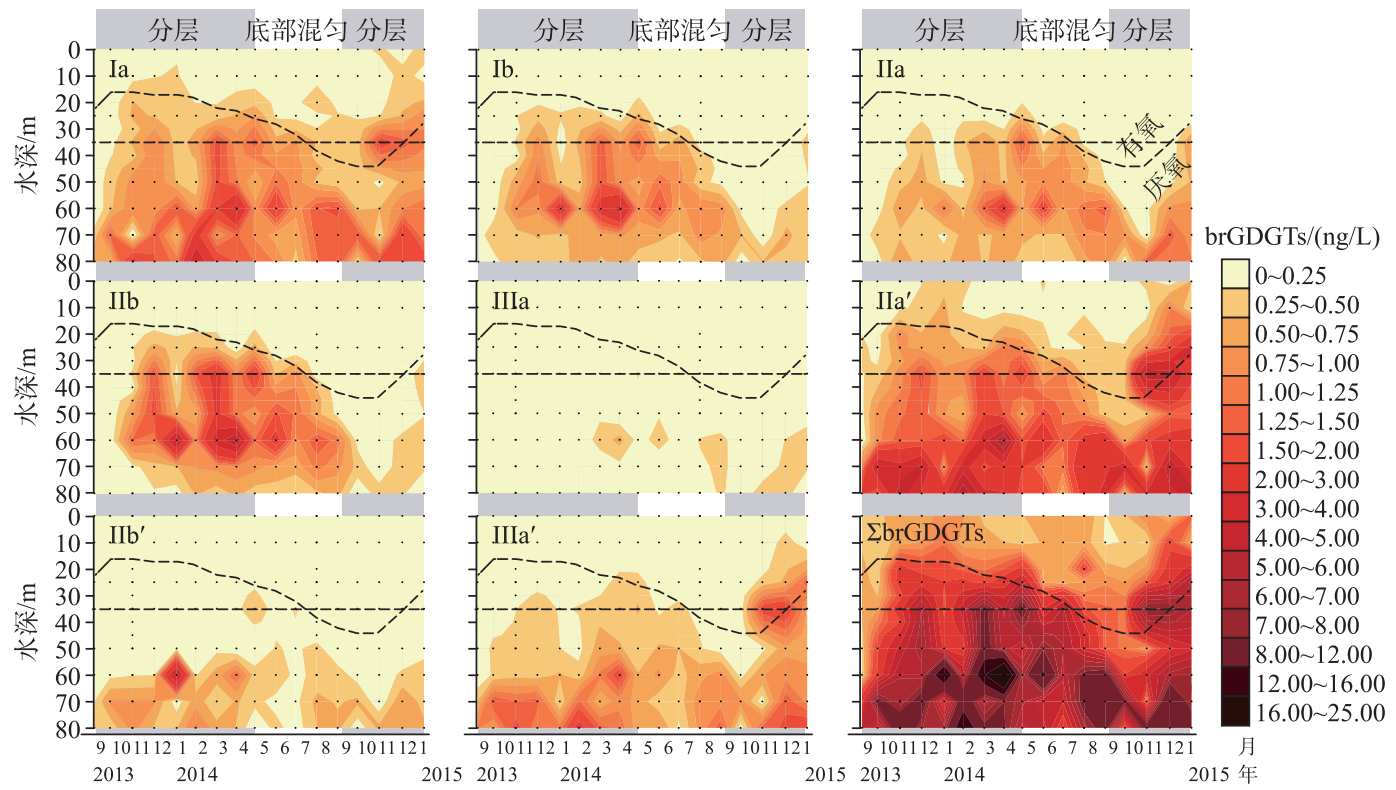

图 4 2013-2015 年期间东非 Chala 湖不同深度水体 brGDGTs 的分布特征(根据文献[38] 修改)

Fig.4 Distribution pattern of brGDGTs in water column from Lake Chala, East Africa during the period of 2013 and 2015(modified from reference [38])

除 Chala 湖以外, 对瑞士深水湖泊 Lugano 湖不同深度水体 brGDGTs 的研究结果也显示, 不同类型 brGDGTs 化合物对水深变化响应各异. 例如, 不携带五元环的 III 系列化合物 ( III a、III $a^{\prime}$ 以及 III a $a^{\prime \prime}$ ) 的浓度在水深 不同层位均最高, 然而这 3 类化合物随水深呈现不同的变化趋势, 其中 III a 随水深逐渐增加, 在深部戻氧水 体中达到最高; 而 III $\mathrm{a}^{\prime}$ 则呈现不一样的变化模式, 在水体上层含氧层位浓度较低, 随水深呈增加的趋势, 并在 水体氧化还原过渡带 (redox transition zone, RTZ) 上部达到最高值, 但在 RTZ 位置, III a'浓度快速降低, 随后 低浓度的 III a $\mathrm{a}^{\prime}$ 随水深趋于稳定 ${ }^{[32]}$. 值得注意的是, 在该湖泊水体中还检测到新被鉴定的 III $\mathrm{a}^{\prime \prime}$ 化合物 ${ }^{[50]}$, 虽然 
仅出现在水体深部的厌氧层位 $(>90 \mathrm{~m})$, 但其浓度随水深逐渐增加, 表明此类新型异构体主要来源于该层 位厌氧细菌的贡献 ${ }^{[32]}$. 此外在其他湖泊的研究结果表明, 水体 brGDGTs 各组分随水深变化的情况不尽相 同, 某些 brGDGTs 化合物在水体不同层位的相对浓度较稳定, 并不会因为水深差异而发生变化, 例如北美 Basin 池塘中的 I 系列化合物 ${ }^{[43]}$ 以及中国东北火山湖的 II $\mathrm{a}^{[48]}$, 但其他化合物如 III 在这两个湖泊均呈现随 水深增加的现象. 需要指出的是, 正是由于不同类型 brGDGTs 化合物随水深的差异性变化, 在一定程度上导 致相关的指标如 MBT、CBT 等也随水深发生变化 ${ }^{[33,43]}$.

需要注意的是,水体 GDGTs 浓度与各组分的变化趋势并不一致,即水深可能会影响 GDGTs 浓度的变 化, 但这并不意味着 GDGTs 各组分也会发生变化. 例如, 瑞士 Lugano 湖以及 Brienz 湖的对比研究发现, 水体 中 isoGDGTs 各组分随水深都呈现降低的趋势, 但相对浓度的变化并不显著, 均以高浓度的 GDGT-0 为主 ${ }^{[16]}$. 类似结果也出现在瑞士的 Rotsee 湖, 水体 GDGTs 浓度也呈现随水深降低的趋势, 但 isoGDGTs 以及 brGDGTs 各组分的相对浓度随水深的变化均不显著, GDGT-0 以及 II a 依然是该湖泊不同深度水体中的最优势组 分 ${ }^{[21]}$. 同样北美 Superior 湖也有类似结果, 虽然在不同季节, 水体 isoGDGTs 浓度均呈现随水深增加的趋势, 但与 Chala 湖水体中变化显著的 GDGT-0 以及 crenarchaeol ${ }^{[27,36]}$ 不同的是, 这两类化合物浓度的变幅都非常 接近, 因此相对浓度并未发生改变, 究其原因可能在于 Superior 湖水体中 isoGDGTs 来源单一, 大多由奇古菌 合成 ${ }^{[40]}$, 而 Chala 湖水体深部的 isoGDGTs 可能有其他非奇古菌来源的贡献, 因此会发生显著变化 ${ }^{[27]}$, 可见 isoGDGTs 的生物来源影响着此类化合物在水体不同层位的分布. 此外, 在瑞士 Lucerne 湖 ${ }^{[39]}$ 以及东 Tanganyika 湖 ${ }^{[31]}$ 也发现类似规律, 即水体中 GDGTs 浓度均随水深而增加, 但各组分之间的相对浓度变化并不显 著, 不同层位水体均以高浓度的 crenarchaeol 为主要组分. 另外在其他湖泊也发现水深对 GDGTs 浓度的改变 要远多于 GDGTs 各化合物的组成,包括北美 Lower King 池塘 ${ }^{[41]}$ 、中国华南湖光岩 ${ }^{[34]}$ 、挪威 Indrepollen 湖 ${ }^{[33]}$ 以及非洲的 Malawi 湖 ${ }^{[45]}$ 等.

\section{2 湖泊水体 GDGTs 生物来源分析}

\section{1 湖泊水体 isoGDGTs 生物来源分析}

来源于古菌的 isoGDGTs 在湖泊水体中分布极广, 几乎覆盖水体的所有层位 ${ }^{[27,31]}$, 然而前人的研究已指 出水体不同层位 isoGDGTs 的分布模式存在差异, 除了水体不同层位环境参数差异这一外因以外, isoGDGTs 不同的生物来源很有可能是造成这些差异的内因. 来自分子生物学的证据显示, 与海洋环境类似, 湖泊水体 以及沉积物中也广泛分布着奇古菌 Thaumarchaeota ${ }^{[51-53]}$, 因此在大多数湖泊, Thaumarchaeota 是合成 isoGDGTs 的主要生物来源之一 ${ }^{[54]}$. 瑞士 Lucerne 湖水体的 SPM、沉积物捕获器以及表层沉积物中 isoGDGTs 的分布模式非常一致, 表明这些化合物可能是同一生物来源, 而高浓度的 crenarchaeol 则表明 Thaumarchaeota 是不同深度水体 isoGDGTs 的主要生物来源之一 ${ }^{[39]}$. 借助克隆以及测序技术等分子生物学 手段分析北美深水湖泊 Superior 湖水体中古菌组成, 结果显示 Thaumarchaeota 是不同深度水体中古菌的主 要组分, 且在系统发生学上与由海洋环境分离的奇古菌 Nitrosopumilus maritimus 非常接近 ${ }^{[55]}$, 在此分子生物 学结果的基础上,结合水体中高浓度的 GDGT-0 与 crenarchaeol 类似的分布特征,作者推测 Superior 湖不同 深度水体 isoGDGTs 主要来源于 Thaumarchaeota 的贡献 ${ }^{[40]}$. 然而需要注意的是, Superior 湖水体 16S rRNA 的 结果显示广古菌 Euryarchaeota 仅分布在深部水体, 在沉积物一水界面处的比例可达 $15 \%$, 表明该湖泊不同 深度水体的古菌分布存在显著差异 ${ }^{[55]}$.

此外, 湖泊环境广泛分布的产甲烷古菌 Methanogens 也是 isoGDGTs 的主要生物来源之一 ${ }^{[56]}$, 除 GDGT-0 以外, 产甲烷古菌也合成其他类型的 isoGDGTs 化合物, 包括 GDGT-1、GDGT-2 以及 GDGT-3(图 1) 等 ${ }^{[57]}$. 前 人的研究显示产甲烷古菌在不同类型湖泊沉积物贡献不同比例的 isoGDGTs ${ }^{[15,58]}$, 除产甲烷古菌合成的其他 生物标志物如古菌醇 (archaeol) 及其碳同位素组成以外, 产甲烷古菌功能基因 $m c r A$ 的检出, 也为产甲烷古菌 在湖泊环境的分布提供分子生物学的证据 ${ }^{[59]}$. 和湖泊沉积物一样, 湖泊水体也分布着产甲烷古菌, 特别是 在厌氧水体, 产甲烷古菌成为 GDGT-0 的主要生物来源 ${ }^{[28,34]}$. 基于此, 有学者提出 GDGT-0/crenarchaeol 指标 以评估产甲烷古菌的贡献程度, 该指标的生物学基础是产甲烷古菌合成 GDGT-0 而无法合成 crenarchaeol, 而奇古菌则可以同时合成这两类化合物, 并指出当该指标大于 2 时, 即代表较多的产甲烷古菌贡献 ${ }^{[28]}$, 随后 
该指标被广泛用于衡量湖泊环境产甲烷古菌贡献的多寡 ${ }^{[60-61]}$.

来源于东非 Chala 湖的研究结果也显示不同深度水体 isoGDGTs 以及古菌群落组成均存在差异. 在对水 体 isoGDGTs 各组分变化的研究中发现, Chala 湖水体上层含氧层 crenarchaeol 与 GDGT-0 浓度相差不大, 但 随着水深增加, 深部厌氧层 GDGT-0 的浓度呈数量级上升, 导致 crenarchaeol 的占比明显下降 ${ }^{[27]}$. Chala 湖水 体分子生物学证据显示水体含氧层的古菌主要是由 Thaumarchaeota I.1a 以及 I.1b 占主导, 这也是该层位 GDGT-0 以及 crenarchaeol 的主要生物来源, 而至于水体深部厌氧层位出现高浓度的 GDGT-0, 作者推测可能 来源于其他古菌的贡献, 包括奇古菌 Thaumarchaeota I.2 和泉古菌 marine benthic group C( MBG-C), 以及隶属 于广古菌的嗜盐古菌 Halobacteriales 等 ${ }^{[27]}$. 随后对该湖泊不同深度水体中指示奇古菌的 $a m o A$ 功能基因分 析发现, $a m o A$ 浓度在水体上部含氧层与下部厌氧层差异显著, 在含氧层中高浓度的 $a m o A$ 指示该层位的古菌 类型主要是奇古菌 Thaumarchaeota I.1a 以及 I.1b, 而深部水体厌氧层位不可培养奇古菌 Thaumarchaeota I.2 型 以及 miscellaneous crenarchaeotic group (MCG) 则是该层位高浓度 GDGT-0 的生物来源 ${ }^{[36]}$. 通过上述对不同 湖泊水体中 isoGDGTs 生物来源的研究不难发现, 合成 isoGDGTs 的生物来源具有多样性的特点, 此外还需注 意的是, 即使在同一湖泊, 水体不同层位也会分布不同类型的古菌, 从而导致不同深度水体中 isoGDGTs 浓 度以及各组分的变化.

\section{2 湖泊水体 brGDGTs 生物来源分析}

与 isoGDGTs 不同, brGDGTs 具体生物来源至今还尚未确定, 虽然在研究初期发现泥炭厌氧层位 brGDGTs 浓度更高, 从而推测合成 brGDGTs 的细菌为厌氧类型 ${ }^{[2,62]}$. 后续对比瑞典 Saxnäs Mosse 泥炭剖面的 $16 \mathrm{~S}$ rRNA 以及 brGDGTs 的分布发现, 酸杆菌 Acidobacteria 是细菌类群的主要组分, 结合该泥炭剖面 brGDGTs 的浓度也较 isoGDGTs 占优势, 推测 Acidobacteria 很有可能是该泥炭高浓度 brGDGTs 的主要来 源 ${ }^{[63]}$. 随后通过分析上覆不同植被类型土壤 brGDGTs 裂解产物的单体碳同位素组成, 揭示合成 brGDGTs 细 菌的碳利用途径, 即这些细菌的营养类型为异养或者兼性异养 ${ }^{[64]}$. 基于此, 有学者通过提取酸杆菌 Acidobacteria 几个亚门菌株膜脂的化学组分, 发现与 brGDGTs 的化学构型非常类似, 因此酸杆菌 Acidobacteria 被推测 是 brGDGTs 最有可能的潜在生物来源之一 ${ }^{[65-66]}$. 而酸杆菌确实在某些土壤和泥炭环境中占据细菌群落的主

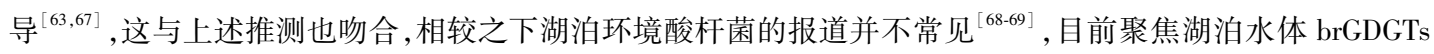
生物来源的研究还非常有限.

最近对瑞士 Lugano 湖的报道指出, 水体中 III a 可以跨越氧化还原过渡带分布, 并随水深呈增加的趋势, 表明在该湖泊中合成 III $\mathrm{a}$ 的细菌可能是厌氧、需氧亦或是兼性厌氧类型, 而其异构体 III $\mathrm{a}^{\prime \prime}$ 仅出现在水深超过 $90 \mathrm{~m}$ 的地方, 因此被认为是由生活在水体深部的厌氧细菌合成 ${ }^{[32]}$. 此外, 该湖泊水体的分子生物学结果显 示, 不同深度水体中 Acidobacteria 的分布特征与 brGDGTs 主要类型一致,且在水体不同层位的变化趋势也与 brGDGTs 的变化类似, 表明在 Lugano 湖酸杆菌是 brGDGTs 的潜在生物来源之一 ${ }^{[32]}$. 然而值得注意的是, brGDGTs 裂解产物烷烃的单体碳同位素结果则表明, 合成 brGDGTs 的细菌也有可能参与水体中的甲烷氧化 作用, 表明该湖泊水体中不同类型 brGDGTs 的生物来源存在差异, 具有多样性 ${ }^{[32]}$. 来自 Chala 湖水体 $16 \mathrm{~S}$ rRNA 的最新研究表明, 水体中某些 brGDGTs 化合物的浓度 ( I b、II b) 与酸杆菌亚门 SD21 基因拷贝数的相 关性非常有限 ${ }^{[38]}$, 可见在 Chala 湖水体中, 酸杆菌并非 brGDGTs 的主要生物来源, 然而在 Lugano 湖水体中 高浓度的 II a III a 与酸杆菌亚门 SD21 的浓度呈显著相关 ${ }^{[32]}$.

\section{3 影响湖泊水体 GDGTs 分布的因素}

\section{1 季节性因素}

3.1 .1 湖泊水体 GDGTs 季节性变化研究 湖泊水体 GDGTs 分布的季节性差异在不同类型湖泊均有报道. 在 对北美 Lower King 池塘两年多的观测发现, 水体 SPM 中 brGDGTs 的浓度以及沉积物捕获器中 brGDGTs 的 通量均有着明显的季节性变化规律, 其中在春季和秋季湖水混匀时期, brGDGTs 通量最高, 约高出低通量时 期两个数量级, 作者推测出现此现象的原因与此时增加的颗粒沉降有关, 但需要注意的是, brGDGTs 各组分 的相对浓度并没有呈现显著的年内或者年际差异 ${ }^{[41]}$. 位于地中海附近利比里亚的一个葟营养喀斯特湖泊 同时开展水体 SPM 以及沉积物捕获器对比研究显示, 该湖泊水体 isoGDGTs 浓度以及通量的高值出现在水 
体分层的 4-9 月期间,有别于上述 Lower King 池塘的结果,作者推测该时段高浓度的 isoGDGTs 可能与以藻 类为食的浮游生物繁盛有关 ${ }^{[49]}$. 上述这两个湖泊水体 GDGTs 分布的季节性差异,除了和合成这些化合物的 生物来源差异有关, 水体的季节性变化所引起的温度、光照以及营养条件的改变也是影响湖泊水体 GDGTs 分布变化的主要原因. 此外还有学者对比分析中国中部东湖水体 isoGDGTs 以及 brGDGTs 的 IPL 以及 CL 部 分的研究,调查结果显示不同类型 GDGTs 的 IPL、CL 部分均表现出明显的季节性变化, 从而引起相关指标 如 IPL isoGDGTs\% 以及 IPL brGDGTs\% 的显著变化, 但考虑到研究对象为城市浅水型湖泊, 相对深水湖泊更 易受环境因素季节性变化的影响 ${ }^{[4]}$.

3.1.2 湖泊水体不同层位 GDGTs 季节性变化研究 与浅水湖泊相比, 深水湖泊更能展示不同深度水体 GDGTs 的季节性变化特征. 例如瑞士深水湖泊 Lucerne 湖, 其表层水体 isoGDGTs 浓度的高值出现在冬季与 来年春季之间, 并在湖水混匀的 1 月份达到最高值, 而深部水体 isoGDGTs 的高值则在夏末和秋季 ${ }^{[39]}$. Lucerne 湖水体 isoGDGTs 的季节性分布变化影响着相关 GDGTs 指标的变化,例如 TEX $\mathrm{X}_{86}$ 指标在表层水体最 高, 高于其他层位, 其最高值通常出现在夏末至秋季, 而深部水体 $\mathrm{TEX}_{86}$ 指标的最高值则出现在 3 月份 ${ }^{[39]}$, 表明不同深度水体 GDGTs 浓度以及相关指标都发生季节性变化. 同样在北美 Lower King 池塘的研究结果也 显示, 不同深度水体 brGDGTs 的季节性变化规律并不一致,首先不同水深 brGDGTs 浓度的季节性变化存在 差异, 表层水体 brGDGTs 浓度在春季和夏初之间最高, 而该时段底层水体中 brGDGTs 浓度略高于表层, 但在 夏末至来年春季湖水混匀的时候, 底层水体 brGDGTs 的浓度则远高于表层, 但在有冰雪覆盖的冬季, 表层水 体 brGDGTs 浓度则高于底层水体 ${ }^{[41]}$. 此外还需要注意的是, 水体表层和底层 brGDGTs 各组分的相对比例也 存在季节性差异,但不携带五元环的 I a II a 以及 III a 系列化合物在水体中的浓度依然占据优势 ${ }^{[41]}$. 然而北 美 Superior 湖连续 3 年的监测结果显示, 位于不同水深的两个沉积物捕获器, 在观测期内其 isoGDGTs 与 brGDGTs 的通量与沉积通量 (mass flux) 之间均显示非常一致的季节性变化特征,在冬季和夏季均呈现显著 的上升趋势 ${ }^{[40]}$, 但通量峰值出现的时间并不完全一致, 存在一定的时间滞后效应, 并且在不同季节这种滞后 时间显现出差异. 此外与上述 Lucerne 湖水体中 $\mathrm{TEX}_{86}$ 指标季节性变化不同的是, Superior 湖不同水深沉积物 捕获器的 $\mathrm{TEX}_{86}$ 指标在不同季节均未发生显著变化 ${ }^{[40]}$. 苏格兰 Lomond 湖不同盆地水体 GDGTs 也呈现不一 致的季节变化特征, 研究显示南部盆地水体中 brGDGTs 在不同季节差别不大, 但在湖泊的北部盆地, 水体 IPL brGDGTs 与 CL brGDGTs 的浓度均在 3 月份出现高值, 且不同季节 crenarchaeol 浓度的高值出现在水体 的不同层位 ${ }^{[42]}$, 研究还显示该湖泊不同水深沉积物捕获器中 IPL GDGTs 也呈现不同的季节变化规律, 表层 水体 GDGTs 通量的季节性变化规律要远远显著于底层 ${ }^{[42]}$. 湖光岩的报道显示, 不同水深沉积物捕获器中 brGDGTs 通量几乎都在冬季达到最高, 但不同水深 brGDGTs 通量的季节性变化并不完全一致, 底部水体的 brGDGTs 通量最高, 同样 SPM 中 brGDGTs 的分布也有着类似的季节性变化规律, 虽然不同层位 brGDGTs 的 浓度差异并不显著, 但表层水体中 brGDGTs 高值出现在冬季, 而底部水体的 brGDGTs 高值则出现在夏季的 6 月份, 可见水体不同层位 brGDGTs 的季节性变化存在着显著差异 ${ }^{[34]}$. 来自北美 Basin 池塘水体不同深度 的 brGDGTs 通量也显示在夏季呈现较低值, 但随后在秋季出现水体分层时, 水体不同层位的 brGDGTs 通量 均呈现明显上升的趋势, 并且水深越深, 通量增加越显著, 据此作者认为湖泊沉积物 brGDGTs 记录的温度信 号实际上是响应的季节信号, 即秋季温度而非年均温 ${ }^{[43]}$.

然而并非所有湖泊水体中的 GDGTs 分布均受季节的影响, 又或者在不同季节所呈现的差异并不显著. 例如瑞士两个水体营养化程度差异很大的湖泊, 水体 GDGTs 的浓度以及各组分的比例在春季和秋季的差别 并不显著,但是水体表层 GDGTs 的浓度在不同季节还是呈现出差异, 在春季 GDGTs 浓度要高于秋季 ${ }^{[16]}$. 此 外中国山西公海水体中 brGDGTs 的浓度在不同月份也未发生显著变化 ${ }^{[47]}$.

\section{2 温度因素}

在湖泊环境, 水深与温度、DO 浓度以及 $\mathrm{pH}$ 值之间往往存在一定的耦合关系, 因此无法独立评估某一环 境因素对水体 GDGTs 分布的影响, 而且从严格意义上来讲, 目前还没有直接证据显示温度影响湖泊水体 GDGTs 的分布, 但众多研究结果均表明水体 GDGTs 敏感响应温度的变化, 首先体现在基于 GDGTs 的分布或 相关指标所恢复的温度往往与实测温度接近.

3.2.1 湖泊水体 isoGDGTs 响应温度变化研究 位于东非 Chala 湖氧跃层之上的沉积物捕获器中基于 $\mathrm{TEX}_{86}$ 
恢复的温度与湖水实测温度一致,因此推测水体中的 isoGDGTs 可能反映水体上部的温度,但是却无法有效 记录湖水温度的季节性变化信号 ${ }^{[27]}$. 而两个营养化程度差异显著的瑞士湖泊研究结果均表明, SPM 的 $\mathrm{TEX}_{86}$ 指标所恢复的温度与湖水表层温度接近, 但相较之下, 表层水体 $\mathrm{TEX}_{86}$ 指标所恢复的温度低于表层水 体的原位实测温度, 而水体底部 $\mathrm{TEX}_{86}$ 所恢复的温度则要高于水体的原位实测温度,据此作者推测可能是由 于不同深度水体 GDGTs 的生物来源差异造成的, 并且位于不同层位水体 isoGDGTs 生长的时间也不尽相同, 因此可能代表着不同时间尺度的温度信号 ${ }^{[16]}$. 但北美 Superior 湖的研究结果则表明, SPM 的 $\mathrm{TEX}_{86}$ 指标在 水体出现分层以及混匀时期均能有效反映水体温度变化, 但基于 $\mathrm{TEX}_{86}$ 所恢复的温度变幅很小, 因此即使在 夏季湖水出现分层时期, 也没有出现较高的恢复温度, 可能与 Chala 湖水体 isoGDGTs 表现一致 ${ }^{[27]}$, 无法有 效记载水温的季节性变化信号 ${ }^{[40]}$. 相较之下, Superior 湖沉积物捕获器中的 $\mathrm{TEX}_{86}$ 指标则不如 SPM 中的 $\mathrm{TEX}_{86}$ 能有效响应温度的变化, 即使在冬季其沉积通量处于最高值的时候, $\mathrm{TEX}_{86}$ 指标也无法有效捕获水体 温度, 但值得注意的是, 沉积物捕获器 $\mathrm{TEX}_{86}$ 指标所恢复的温度与同一地点表层沉积物的 $\mathrm{TEX}_{86}$ 指标所恢复 的温度一致, 均接近水体 $40 \mathrm{~m}$ 水深处的温度 ${ }^{[40]}$. 来自苏格兰 Lomond 湖的结果则显示, 位于水深 $30 \sim 60 \mathrm{~m}$ 处的 SPM, 其 $\mathrm{TEX}_{86}$ 指标恢复的温度与实测水温之间非常接近 ${ }^{[42]}$. 综上, 这些湖泊水体 SPM 中 isoGDGTs 的 分布敏感响应温度的变化,特别是基于 isoGDGTs 的 $\mathrm{TEX}_{86}$ 指标所恢复的温度有效指示实测温度.

然而不容忽视的是, 奇古菌 Thaumarchaeota 的生态学特征可能在一定程度上影响 $\mathrm{TEX}_{86}$ 指标所恢复温 度的准确性. 例如瑞士深水湖泊 Lucerne 湖的研究结果显示, 虽然浅层水体的 $\mathrm{TEX}_{86}$ 指标呈现明显的季节性 变化特征, 但却无法有效反映湖水表层温度的变化, 相反位于热跃层以下 Thaumarchaeota 生长较多的深部水 体, $\mathrm{TEX}_{86}$ 所恢复的温度与实测温度接近 ${ }^{[39]}$. 这与 Chala 湖结果一致, 水体 $\mathrm{TEX}_{86}$ 所重建的温度不是指示水体 表层的温度, 而是反映奇古菌 Thaumarchaeota 繁盛时期氧跃层的温度 ${ }^{[36]}$. 此外在非洲 Malawi 湖中发现, 水 体 $\mathrm{TEX}_{86}$ 所恢复的温度, 在表层水体要低于原位实测温度, 但在次表层水体则要高于原位实测温度, 作者认 为造成该现象的原因是生活在不同层位水体的古菌类群及其生态型差异 ${ }^{[45]}$. 虽然目前还没有湖泊方面的 研究工作来佐证, 但海洋环境方面的证据显示 $\mathrm{TEX}_{86}$ 恢复的温度究竟高于还是低于实测温度, 主要取决于水 体中占主导奇古菌 Thaumarchaeota 的生态型, 因为氨氧化速率与 $\mathrm{TEX}_{86}$ 之间呈现负相关, 浅水层位的奇古菌 大多生长在高浓度的铵条件下, 所恢复的温度偏低; 而深水层位的奇古菌则大多适应低浓度的铵, 所恢复的 温度偏暖 ${ }^{[70-72]}$. 因此 Malawi 湖相对较深水体 $\mathrm{TEX}_{86}$ 所恢复的温度较实测值偏高, 可能是由于生活在深水层 位的奇古菌群落影响 isoGDGTs 的分布 ${ }^{[45]}$. 此外, 在评估水体 isoGDGTs 响应温度的过程中还需要考虑其他 古菌的影响, 例如东非深水湖泊坦噶尼喀湖的结果显示, 水体 $\mathrm{TEX}_{86}$ 并不能有效指示水体原位实测温度的信 息, $\mathrm{TEX}_{86}$ 值仅在表层水体与实测温度接近,在水体次表层所恢复的温度则要明显高于水体的原位实测温 度,据此作者推测可能是与水体 isoGDGTs 有其他非奇古菌来源的贡献有关 ${ }^{[31]}$.

3.2.2 湖泊水体 brGDGTs 响应温度变化研究 北美 Lower King 池塘 SPM 的结果显示, brGDGTs 分布不仅有 效记录水温的变化, 还可以指示温度的季节性变化规律, 然而沉积物捕获器中的 brGDGTs 却无法有效捕捉 温度变化的信号, 表明水体中的 brGDGTs 可能无法沉降或保存到沉积物中 ${ }^{[41]}$. 不过在湖水分层时期, 沉积 物捕获器中的 brGDGTs 可以反映底层水体的温度, 虽然所恢复的温度与实测水温之间并非完全一致, 但实 测水温与几类 brGDGTs 化合物之间均存在较好的相关性 ${ }^{[41]}$. 东非 Chala 湖水体 brGDGTs 的指标, 包括 MBT 以及 DC( degree of cyclization, 去对数化的环化指标) 能有效指示水温信息, 这些指标均与水温之间存在显著 的正相关关系, 并且在剔除水深较深的样品之后, 与水温的相关性得以提高, 表明该湖泊水体中合成 brGDGTs 的细菌可以根据温度来调整自身细胞膜脂组成 ${ }^{[37]}$. 然而需要注意的是, 基于 brGDGTs 恢复的温度 与实测气温以及水温之间均存在一定的滞后性, 其中滞后于气温约 $5 \sim 6$ 个月, 水温则是 3 个月, 这可能是由 于湖泊水体 brGDGTs 与在温度重建时所利用的湖泊沉积物 brGDGTs, 两者对温度有着不同的响应有关, 因 为后者的来源要较前者复杂, 除湖泊水体自生 brGDGTs 以外, 湖泊周边土壤以及沉积物自身等也会贡献 $\operatorname{brGDGTs}^{[37]}$, 此外这种重建温度与实测温度之间的滞后效应在 Lower King 池塘中也有报道 ${ }^{[41]}$.

另外,研究显示温度也会影响水体 brGDGTs 新分离的各类异构体的分布. 对中国华北地区公海水体的 研究发现, $\mathrm{SPM}$ 的 $\mathrm{MBT}_{5 \mathrm{ME}}^{\prime}$ 和 $\mathrm{MBT}_{6 \mathrm{ME}}^{\prime}$ 指标在 9 月份均随水深呈现降低的趋势, 这与实测水体温度的变化模式 一致,然而这两个指标在 1 月份并没有发生变化,也与 1 月份相对稳定的水温变化模式一致,据此认为该湖 
泊水体中基于 SPM 的 brGDGTs 及其异构体的分布模式有效反映水温的变化 ${ }^{[47]}$. 然而需要注意的是, 虽然这 两个指标可以有效指示水温的变化, 但所恢复的不同月份温差明显低于实测值 ${ }^{[47]}$, 类似现象在其他湖泊也 有发生,例如北美 Lower King 池塘, 基于表层水体 SPM 恢复的季节性温差为 $5.4^{\circ} \mathrm{C}$, 而实际温差则可达到 $28.3^{\circ} \mathrm{C}^{[41]}$; 华南地区湖光岩基于 brGDGTs 计算出的季节温差为 $8^{\circ} \mathrm{C}$, 而实际季节温差可达 $16^{\circ} \mathrm{C}^{[34]}$.

\section{3 水深和水体 DO 浓度因素}

研究显示除温度以外, 水体 DO 的浓度也会影响湖泊不同深度水体 GDGTs 的分布. 例如东非 Chala 湖水 体深部厌氧层位 isoGDGTs 的浓度要高出上层水体两个数量级, 并且不同层位古菌群落组成也存在差异 ${ }^{[27]}$, 此外水体自生的 brGDGTs 大多生活在水深 35 43 m 处、氧浓度较低 $\left(\mathrm{O}_{2}<2 \mathrm{mg} / \mathrm{L}\right)$ 的深部水体, 表明在该湖 泊水体中合成 brGDGTs 的细菌偏好低氧浓度的环境 ${ }^{[37]}$. 同样在挪威 Indrepollen 湖水体中也发现类似规律, isoGDGTs 的总浓度随着 DO 的减少而增加, 并在氧跃层底部达到最高值, 两者之间呈现非常显著的负相关, 结果还显示 $\mathrm{DO}$ 浓度而非温度是影响该湖泊水体 $\mathrm{TEX}_{86}$ 的首要因素 ${ }^{[33]}$. 类似结果也出现在地中海附近的塞 营养湖泊, 对比结果显示水体上层 SPM 和沉积物捕获器的 $\mathrm{TEX}_{86}$ 均表现出显著的季节性特征, 所恢复的温 度与表层水温吻合 ${ }^{[49]}$, 相较之下位于湖泊深部的缺氧层, $\mathrm{TEX}_{86}$ 与水体 $\mathrm{DO}$ 浓度之间也存在着明显的负相 关, 导致湖泊表层沉积物的 $\mathrm{TEX}_{86}$ 信号受水体 DO 浓度的影响, 因此在缺氧环境使用 $\mathrm{TEX}_{86}$ 指标恢复温度时 可能会产生误差 ${ }^{[49]}$. 值得注意的是, 几株海洋奇古菌 Thaumarchaeota 的模拟结果可以为上述现象提供生物 学基础, 研究显示氧气浓度影响奇古菌膜脂中的 isoGDGTs 组分, 特别是当氧气浓度受限时, GDGT-2 和 GDGT-3 浓度增加, 而 GDGT-1 的浓度减少, 从而影响 $\mathrm{TEX}_{86}$ 值, 导致其所恢复温度的变化 ${ }^{[70]}$, 因此在利用 $\mathrm{TEX}_{86}$ 指标恢复温度时需考虑 $\mathrm{DO}$ 浓度的影响.

\section{4 其他因素}

除温度、DO 浓度等因素以外, 其他因素包括湖水 $\mathrm{pH}$ 值、富营养化程度、降水等也会影响水体中 GDGTs 的分布. 例如 Chala 湖, 虽然基于 brGDGTs 的 DC 以及 CBT 指标与温度之间的相关性依然最显著, 但 $\mathrm{pH}$ 与 MBT 之间也呈现较高的相关性 ${ }^{[37]}$. 但在该湖泊开展的最新研究显示, 不同深度水体 brGDGTs 与温度、pH 以 及 DO 浓度之间的关系并不显著, 但却有效响应水体分层以及深部水体的混合, 表明在 Chala 湖, 温度可能 并不是影响水体中 brGDGTs 分布的首要因子, 水体分层混合效应等所引起的细菌群落变化也会影响水体 brGDGTs 的分布 ${ }^{[38]}$. 值得注意的是, 降水也在一定程度上影响东湖水体中 GDGTs 的分布, 特别是 brGDGTs 的 I / II 比值可以有效指示降水量, 较高的 I / II 比值意味着湖泊周边土壤中以 I 为主的 brGDGTs 被冲刷至 湖泊, 从而覆盖以 II 为主的湖泊沉积物, 至于降水对湖泊水体 GDGTs 分布有如此直接的影响, 可能与该湖泊 水深较浅, 更易受外界水源输人的影响有关 ${ }^{[44]}$. 此外, 水深以及富营养化等因素也在一定程度上影响着水 体 GDGTs 的分布, 如中国东部火山湖泊不同深度水体中, 水深与 III a I I 之间分别存在着明显的正、负相关的 关系, brGDGTs 组分的变化可以反映湖泊水体中氧化还原条件的变化, 指示水体中 DO 浓度特征 ${ }^{[48]}$, 而水体 的富营养化以及氧化还原分层等作用在一定程度上推动合成 brGDGTs 细菌的生长和繁盛等 ${ }^{[32]}$.

\section{4 结论}

本文主要聚焦微生物膜脂来源的四醚类化合物在湖泊水体中的分布研究, 分别介绍来源于古菌的 isoGDGTs 以及细菌的 brGDGTs 在湖泊不同深度水体中的分布特征,包括浓度以及各组分相对浓度随水深的变 化情况研究, 此外还归纳总结湖泊水体中不同类型 GDGTs 的生物来源问题分析, 以及影响湖泊水体 GDGTs 分 布的主要因素等. 虽然相较于在全球尺度上广泛开展的湖泊沉积物研究, 湖泊水体 GDGTs 的研究工作起步尚 晚,但前人这 10 年来对湖泊水体 GDGTs 的研究表明,GDGTs 几乎分布在湖泊水体的所有层位,水深影响水体 GDGTs 浓度以及各组分的变化, 并且不同类型湖泊 GDGTs 随水深变化的规律并不一致, 在大多数湖泊会呈现 显著增加或者减少的变化,而在某些湖泊则并没有发生明显的变化,这可能与不同湖泊水体中 GDGTs 的生物 来源以及环境条件 (温度、含氧量、营养程度等) 的差异有关. 关于水体 isoGDGTs 的生物来源问题, 除了水体中 广泛分布的奇古菌 Thaumarchaeota、产甲烷古菌 Methanogens 以外, 其他类型的泉古菌如 MBG-C 和 MCG、以及 广古菌等也能合成 isoGDGTs. 而水体中 brGDGTs 的生物来源, 可能与土壤以及泥炭中的研究结果类似, 即大多 来源于酸杆菌Acidobacteria 的贡献,然而在某些湖泊, 水体中酸杆菌 Acidobacteria 的丰度与 brGDGTs 浓度之间 
的关系并不显著,因此酸杆菌可能并不是此类湖泊水体 brGDGTs 的主要生物来源.

当然,湖泊水体 GDGTs 研究中也存在着其他亟需解决的问题,例如利用水体 GDGTs 分布定量重建温度 时往往出现滞后的现象, 即基于 SPM 或者沉积物捕获器中 GDGTs 的分布所恢复的温度, 虽然与实测温度吻 合, 但往往与实测温度之间出现时间上的错位, 究竟这种滞后效应是否具有普遍性, 以及不同湖泊的滞后时 间是否一致,并且如何量化等问题. 此外湖泊水体 GDGTs 具体生物来源问题, 以及不同生物来源 GDGTs 对 温度或者其他环境因素响应问题, 还有湖泊周边土壤 GDGTs 对水体 GDGTs 贡献率以及湖泊水体 GDGTs 对 湖泊沉积物的贡献率问题等,均需要进一步研究.

致谢: 感谢中国科学院地球环境研究所姚远博士在论文撰写过程中提供的帮助.

\section{5 参考文献}

[ 1 ] Schouten S, Hopmans EC, Sinninghe Damsté JS. The organic geochemistry of glycerol dialkyl glycerol tetraether lipids: A review. Organic Geochemistry, 2013, 54: 19-61. DOI: 10.1016/j.orggeochem.2012.09.006.

[ 2 ] Weijers JWH, Schouten S, Hopmans EC et al. Membrane lipids of mesophilic anaerobic bacteria thriving in peats have typical archaeal traits. Environmental Microbiology, 2006, 8(4) : 648-657. DOI: 10.1111/j.1462-2920.2005.00941.x.

[ 3 ] Liu XL, Lipp JS, Simpson JH et al. Mono- and dihydroxyl glycerol dibiphytanyl glycerol tetraethers in marine sediments: Identification of both core and intact polar lipid forms. Geochimica et Cosmochimica Acta, 2012, 89: 102-115. DOI: 10. 1016/j.gca.2012.04.053.

[ 4 ] Naafs BDA, McCormick D, Inglis GN et al. Archaeal and bacterial H-GDGTs are abundant in peat and their relative abundance is positively correlated with temperature. Geochimica et Cosmochimica Acta, 2018, 227: 156-170. DOI: 10.1016/j. gca.2018.02.025.

[ 5 ] Baxter AJ, Hopmans EC, Russell JM et al. Bacterial GMGTs in East African lake sediments: Their potential as palaeotemperature indicators. Geochimica et Cosmochimica Acta, 2019, 259: 155-169. DOI: 10.1016/j.gca.2019.05.039.

[ 6 ] De Jonge C, Hopmans EC, Stadnitskaia A et al. Identification of novel penta- and hexamethylated branched glycerol dialkyl glycerol tetraethers in peat using HPLC-MS ${ }^{2}$, GC-MS and GC-SMB-MS. Organic Geochemistry, 2013, 54: 78-82. DOI: $10.1016 /$ j.orggeochem.2012.10.004.

[ 7 ] Becker KW, Lipp JS, Zhu C et al. An improved method for the analysis of archaeal and bacterial ether core lipids. Organic Geochemistry, 2013, 61: 34-44. DOI: 10.1016/j.orggeochem.2013.05.007.

[ 8 ] Li JJ, Xie SC. Application of microbial membrane tetraether lipids in lacustrine environments: A review. Bulletin of Mineralogy, Petrology and Geochemistry, 2015, 34(2): 277-284, 309. [李婧婧, 谢树成. 微生物四醚膜脂化合物在湖泊 环境中的研究进展. 矿物岩石地球化学通报, 2015, 34(2): 277-284, 309.]

[ 9 ] Li J, Yang H, Gao C et al. Application of hydroxylated glycerol dialkyl glycerol tetraethers: A review. Quaternary Sciences, 2018, 38 (6) : 1462-1470. [李婧婧, 杨欢, 高超等. 差基甘油二烷基甘油四醚脂类化合物研究进展. 第四纪 研究, 2018, 38(6) : 1462-1470.]

[10] Naafs BDA, Inglis GN, Zheng Y et al. Introducing global peat-specific temperature and pH calibrations based on brGDGT bacterial lipids. Geochimica et Cosmochimica Acta, 2017, 208: 285-301. DOI: 10.1016/j.gca.2017.01.038.

[11] Castañeda IS, Schouten S. A review of molecular organic proxies for examining modern and ancient lacustrine environments. Quaternary Science Reviews, 2011, 30(21/22) : 2851-2891. DOI: 10.1016/j.quascirev.2011.07.009.

[12] Schouten S, Hopmans EC, Schefuß E et al. Distributional variations in marine crenarchaeotal membrane lipids: A new tool for reconstructing ancient sea water temperatures? Earth and Planetary Science Letters, 2002, 204(1/2) : 265-274. DOI: 10.1016/S0012-821X( 02) 00979-2.

[13] Wuchter C, Schouten S, Coolen MJL et al. Temperature-dependent variation in the distribution of tetraether membrane lipids of marine Crenarchaeota: Implications for TEX86 paleothermometry. Paleoceanography, 2004, 19(4) : PA4028. DOI: 10.1029/2004pa001041.

[14] Weijers JWH, Schouten S, van den Donker JC et al. Environmental controls on bacterial tetraether membrane lipid distribution in soils. Geochimica et Cosmochimica Acta, 2007, 71(3) : 703-713. DOI: 10.1016/j.gca.2006.10.003.

[15] Li JJ, Pancost RD, Naafs BDA et al. Distribution of glycerol dialkyl glycerol tetraether (GDGT) lipids in a hypersaline lake system. Organic Geochemistry, 2016, 99: 113-124. DOI: 10.1016/j.orggeochem.2016.06.007. 
[16] Bechtel A, Smittenberg RH, Bernasconi SM et al. Distribution of branched and isoprenoid tetraether lipids in an oligotrophic and a eutrophic Swiss lake: Insights into sources and GDGT-based proxies. Organic Geochemistry, 2010, 41 (8) : 822-832. DOI: 10.1016/j.orggeochem.2010.04.022.

[17] Niemann H, Stadnitskaia A, Wirth SB et al. Bacterial GDGTs in Holocene sediments and catchment soils of a high Alpine lake: application of the MBT/CBT-paleothermometer. Climate of the Past, 2012, 8(3): 889-906.

[18] Li JJ, Kong LY, Yang H et al. Temperature variations since $1750 \mathrm{CE}$ inferred from an alpine lake in the southeastern margin of the Tibetan Plateau. Quaternary International, 2017, 436: 37-44. DOI: 10.1016/j.quaint.2016.12.016.

[19] Watson BI, Williams JW, Russell JM et al. Temperature variations in the southern Great Lakes during the last deglaciation: Comparison between pollen and GDGT proxies. Quaternary Science Reviews, 2018, 182: 78-92. DOI: 10.1016/j. quascirev.2017.12.011.

[20] Tierney JE, Russell JM. Distributions of branched GDGTs in a tropical lake system: Implications for lacustrine application of the MBT/CBT paleoproxy. Organic Geochemistry, 2009, 40 (9) : 1032-1036. DOI: 10. 1016/j. orggeochem. 2009. 04.014 .

[21] Naeher S, Peterse F, Smittenberg RH et al. Sources of glycerol dialkyl glycerol tetraethers (GDGTs) in catchment soils, water column and sediments of Lake Rotsee (Switzerland) - Implications for the application of GDGT-based proxies for lakes. Organic Geochemistry, 2014, 66: 164-173. DOI: 10.1016/j.orggeochem.2013.10.017.

[22] Tierney JE, Russell JM, Eggermont $\mathrm{H}$ et al. Environmental controls on branched tetraether lipid distributions in tropical East African lake sediments. Geochimica et Cosmochimica Acta, 2010, 74(17) : 4902-4918. DOI: 10.1016/j.gca.2010. 06.002 .

[23] Sun Q, Chu GQ, Liu MM et al. Distributions and temperature dependence of branched glycerol dialkyl glycerol tetraethers in recent lacustrine sediments from China and Nepal. Journal of Geophysical Research Atmospheres, 2011, 116( G1): G01008. DOI: $10.1029 / 2010 j g 001365$.

[24] Pearson EJ, Juggins S, Talbot HM et al. A lacustrine GDGT-temperature calibration from the Scandinavian Arctic to Antarctic: Renewed potential for the application of GDGT-paleothermometry in lakes. Geochimica et Cosmochimica Acta, 2011, 75(20) : 6225-6238. DOI: 10.1016/j.gca.2011.07.042.

[25] Dang XY, Ding WH, Yang H et al. Different temperature dependence of the bacterial brGDGT isomers in 35 Chinese lake sediments compared to that in soils. Organic Geochemistry, 2018. 119: 72-79.

[26] Russell JM, Hopmans EC, Loomis SE et al. Distributions of 5- and 6-methyl branched glycerol dialkyl glycerol tetraethers (brGDGTs) in East African lake sediment: Effects of temperature, $\mathrm{pH}$, and new lacustrine paleotemperature calibrations. Organic Geochemistry, 2018, 117: 56-69. DOI: 10.1016/j.orggeochem.2017.12.003.

[27] Sinninghe Damsté JS, Ossebaar J, Abbas B et al. Fluxes and distribution of tetraether lipids in an equatorial African lake: Constraints on the application of the TEX86 palaeothermometer and BIT index in lacustrine settings. Geochimica et Cosmochimica Acta, 2009, 73(14) : 4232-4249. DOI: 10.1016/j.gca.2009.04.022.

[28] Blaga CI, Reichart GJ, Heiri O et al. Tetraether membrane lipid distributions in water-column particulate matter and sediments: A study of 47 European lakes along a north-south transect. Journal of Paleolimnology, 2009, 41(3) : 523-540. DOI: $10.1007 / \mathrm{s} 10933-008-9242-2$.

[29] Sinninghe Damsté JS, Rijpstra WIC, Hopmans EC et al. Intact polar and core glycerol dibiphytanyl glycerol tetraether lipids of group I.1a and I.1b thaumarchaeota in soil. Applied and Environmental Microbiology, 2012, 78(19) : 6866-6874. DOI: $10.1128 /$ aem.01681-12.

[30] Schouten S, Hopmans EC, Pancost RD et al. Widespread occurrence of structurally diverse tetraether membrane lipids: Evidence for the ubiquitous presence of low-temperature relatives of hyperthermophiles. PNAS, 2000, 97 (26) : 1442114426. DOI: 10.1073 /pnas.97.26.14421.

[31] Schouten S, Rijpstra WIC, Durisch-Kaiser E et al. Distribution of glycerol dialkyl glycerol tetraether lipids in the water column of Lake Tanganyika. Organic Geochemistry, 2012, 53: 34-37. DOI: 10.1016/j.orggeochem.2012.01.009.

[32] Weber Y, Sinninghe Damsté JS, Zopfi J et al. Redox-dependent niche differentiation provides evidence for multiple bacterial sources of glycerol tetraether lipids in lakes. PNAS, 2018, 115(43) : 10926-10931. DOI: 10.1073/pnas.1805186115.

[33] Zhang ZH, Smittenberg RH, Bradley RS. GDGT distribution in a stratified lake and implications for the application of TEX 86 in paleoenvironmental reconstructions. Scientific Reports, 2016, 6: 34465. DOI: 10.1038/srep34465. 
[34 ] Hu JF, Zhou HD, Peng PA et al. Seasonal variability in concentrations and fluxes of glycerol dialkyl glycerol tetraethers in Huguangyan Maar Lake, SE China: Implications for the applicability of the MBT-CBT paleotemperature proxy in lacustrine settings. Chemical Geology, 2016, 420: 200-212. DOI: 10.1016/j.chemgeo.2015.11.008.

[35] Pitcher A, Hopmans EC, Schouten S et al. Separation of core and intact polar archaeal tetraether lipids using silica columns: Insights into living and fossil biomass contributions. Organic Geochemistry, 2009, 40(1) : 12-19. DOI: 10.1016/j. orggeochem.2008.09.008.

[36] Buckles LK, Villanueva L, Weijers JWH et al. Linking isoprenoidal GDGT membrane lipid distributions with gene abundances of ammonia-oxidizing Thaumarchaeota and uncultured crenarchaeotal groups in the water column of a tropical lake (Lake Challa, East Africa). Environmental Microbiology, 2013, 15(9) : 2445-2462. DOI: 10.1111/1462-2920.12118.

[37] Buckles LK, Weijers JWH, Verschuren D et al. Sources of core and intact branched tetraether membrane lipids in the lacustrine environment: Anatomy of Lake Challa and its catchment, equatorial East Africa. Geochimica et Cosmochimica Ac$t a, 2014,140$ : 106-126. DOI: 10.1016/j.gca.2014.04.042.

[38 ] van Bree LGJ, Peterse F, Baxter AJ et al. Seasonal variability and sources of in situ brGDGT production in a permanently stratified African crater lake. Biogeosciences, 2020, 17(21) : 5443-5463. DOI: 10.5194/bg-17-5443-2020.

[39] Blaga CI, Reichart GJ, Vissers EW et al. Seasonal changes in glycerol dialkyl glycerol tetraether concentrations and fluxes in a perialpine lake: Implications for the use of the TEX86 and BIT proxies. Geochimica et Cosmochimica Acta, 2011, 75 (21) : 6416-6428. DOI: 10.1016/j.gca.2011.08.016.

[40] Woltering M, Werne JP, Kish JL et al. Vertical and temporal variability in concentration and distribution of thaumarchaeotal tetraether lipids in Lake Superior and the implications for the application of the TEX86 temperature proxy. Geochimica et Cosmochimica Acta, 2012, 87: 136-153. DOI: 10.1016/j.gca.2012.03.024.

[41] Loomis SE, Russell JM, Heureux AM et al. Seasonal variability of branched glycerol dialkyl glycerol tetraethers (brGDGTs) in a temperate lake system. Geochimica et Cosmochimica Acta, 2014, 144: 173-187. DOI: 10.1016/j.gca.2014. 08.027.

[42] Buckles LK, Weijers JWH, Tran XM et al. Provenance of tetraether membrane lipids in a large temperate lake (Loch Lomond, UK) : Implications for glycerol dialkyl glycerol tetraether (GDGT)-based palaeothermometry. Biogeosciences, 2014, 11(19) : 5539-5563. DOI: 10.5194/bg-11-5539-2014.

[43] Miller DR, Habicht MH, Keisling BA et al. A 900-year New England temperature reconstruction from in situ seasonally produced branched glycerol dialkyl glycerol tetraethers (brGDGTs). Climate of the Past, 2018, 14(11): 1653-1667. DOI: $10.5194 / \mathrm{cp}-14-1653-2018$.

[44] Qian S, Yang H, Dong CH et al. Rapid response of fossil tetraether lipids in lake sediments to seasonal environmental variables in a shallow lake in central China: Implications for the use of tetraether-based proxies. Organic Geochemistry, 2019, 128: 108-121. DOI: 10.1016/j.orggeochem.2018.12.007.

[45] Meegan Kumar D, Woltering M, Hopmans EC et al. The vertical distribution of Thaumarchaeota in the water column of Lake Malawi inferred from core and intact polar tetraether lipids. Organic Geochemistry, 2019, 132: 37-49. DOI: 10. 1016/j.orggeochem.2019.03.004.

[46] Yao Y, Zhao JJ, Bauersachs T et al. Effect of water depth on the TEX86 proxy in volcanic lakes of northeastern China. Organic Geochemistry, 2019, 129: 88-98. DOI: 10.1016/j.orggeochem.2019.01.014.

[47] Cao JT, Rao ZG, Shi FX et al. Ice formation on lake surfaces in winter causes warm-season bias of lacustrine brGDGT temperature estimates. Biogeosciences, 2020, 17(9) : 2521-2536. DOI: 10.5194/bg-17-2521-2020.

[48] Yao Y, Zhao JJ, Vachula RS et al. Correlation between the ratio of 5-methyl hexamethylated to pentamethylated branched GDGTs $\left(\mathrm{HP}_{5}\right)$ and water depth reflects redox variations in stratified lakes. Organic Geochemistry, 2020, 147: 104076. DOI: 10.1016/j.orggeochem.2020.104076.

[49] Cao M, Rivas-Ruiz P, Trapote MDC et al. Seasonal effects of water temperature and dissolved oxygen on the isoGDGT proxy (TEX86) in a Mediterranean oligotrophic lake. Chemical Geology, 2020, 551: 119759. DOI: 10.1016/j.chemgeo. 2020.119759.

[50] Weber Y, De Jonge C, Rijpstra WIC et al. Identification and carbon isotope composition of a novel branched GDGT isomer in lake sediments: Evidence for lacustrine branched GDGT production. Geochimica et Cosmochimica Acta, 2015, 154: 118-129. DOI: $10.1016 /$ j.gca.2015.01.032. 
[51] Keough BP, Schmidt TM, Hicks RE. Archaeal nucleic acids in picoplankton from great lakes on three continents. Microbial Ecology, 2003, 46(2) : 238-248. DOI: 10.1007/s00248-003-1003-1.

[52] Kan JJ, Clingenpeel S, Macur RE et al. Archaea in Yellowstone lake. The ISME Journal, 2011, 5(11) : 1784-1795. DOI: $10.1038 /$ ismej.2011.56.

[53] Ochsenreiter T, Selezi D, Quaiser A et al. Diversity and abundance of Crenarchaeota in terrestrial habitats studied by $16 \mathrm{~S}$ RNA surveys and real time PCR. Environmental Microbiology, 2003, 5(9) : 787-797. DOI: 10.1046/j.1462-2920.2003. 00476.x.

[54] Woltering ML. Thaumarchaeota distribution in the water columns of Lakes Superior and Malawi: Implications for the $\mathrm{TEX}_{86}$ lacustrine temperature proxy [Dissertation]. Duluth: University of Minnesota, 2011.

[55] Kish JL. Planktonic archaeal communities change seasonally in Lake Superior, 2010.

[56] Llirós M, Gich F, Plasencia A et al. Vertical distribution of ammonia-oxidizing crenarchaeota and methanogens in the epipelagic waters of lake Kivu (Rwanda-democratic republic of the Congo). Applied and Environmental Microbiology, 2010, 76(20) : 6853-6863. DOI: 10.1128/aem.02864-09.

[57] Bauersachs T, Weidenbach K, Schmitz RA et al. Distribution of glycerol ether lipids in halophilic, methanogenic and hyperthermophilic Archaea. Organic Geochemistry, 2015, 83/84: 101-108. DOI: 10.1016/j.orggeochem.2015.03.009.

[58] Naeher S, Niemann H, Peterse F et al. Tracing the methane cycle with lipid biomarkers in Lake Rotsee (Switzerland). Organic Geochemistry, 2014, 66: 174-181. DOI: 10.1016/j.orggeochem.2013.11.002.

[59] Li JJ, Pancost RD, Naafs BDA et al. Multiple environmental and ecological controls on archaeal ether lipid distributions in saline ponds. Chemical Geology, 2019, 529: 119293. DOI: 10.1016/j.chemgeo.2019.119293.

[60] Wang MD, Tian Q, Li XM et al. TEX86 as a potential proxy of lake water pH in the Tibetan Plateau. Palaeogeography, Palaeoclimatology, Palaeoecology, 2020, 538: 109381. DOI: 10.1016/j.palaeo.2019.109381.

[61] Sun W, Zhang E, Chang J et al. Archaeal lipid-inferred paleohydrology and paleotemperature of Lake Chenghai during the Pleistocene-Holocene transition. Clim. Past, 2020, 16(3) : 833-845.

[62] Peterse F, Hopmans EC, Schouten S et al. Identification and distribution of intact polar branched tetraether lipids in peat and soil. Organic Geochemistry, 2011, 42(9) : 1007-1015. DOI: 10.1016/j.orggeochem.2011.07.006.

[63] Weijers JWH, Panoto E, van Bleijswijk J et al. Constraints on the biological source(s) of the orphan branched tetraether membrane lipids. Geomicrobiology Journal, 2009, 26(6) : 402-414. DOI: 10.1080/01490450902937293.

[64] Weijers JWH, Wiesenberg GLB, Bol R et al. Carbon isotopic composition of branched tetraether membrane lipids in soils suggest a rapid turnover and a heterotrophic life style of their source organism (s). Biogeosciences, 2010, 7(9) : 29592973. DOI: 10.5194/bg-7-2959-2010.

[65 ] Sinninghe Damsté JS, Rijpstra WIC, Hopmans EC et al. 13, 16-dimethyl octacosanedioic acid (iso-diabolic acid), a common membrane-spanning lipid of acidobacteria subdivisions 1 and 3. Applied and Environmental Microbiology, 2011, 77 (12) : 4147-4154. DOI: 10.1128/aem.00466-11.

[66] Sinninghe Damsté JS, Rijpstra WIC, Hopmans EC et al. Ether- and ester-bound iso-diabolic acid and other lipids in members of acidobacteria subdivision 4. Applied and Environmental Microbiology, 2014, 80(17) : 5207-5218. DOI: 10.1128/ aem.01066-14.

[67] Jones RT, Robeson MS, Lauber CL et al. A comprehensive survey of soil acidobacterial diversity using pyrosequencing and clone library analyses. The ISME Journal, 2009, 3(4) : 442-453. DOI: 10.1038/ismej.2008.127.

[68 ] Zimmermann J, Portillo MC, Serrano L et al. Acidobacteria in freshwater ponds at doñana National Park, Spain. Microbial Ecology, 2012, 63(4) : 844-855. DOI: 10.1007/s00248-011-9988-3.

[69] Preheim SP, Olesen SW, Spencer SJ et al. Surveys, simulation and single-cell assays relate function and phylogeny in a lake ecosystem. Nature Microbiology, 2016, 1(9) : 1-9. DOI: 10.1038/nmicrobiol.2016.130.

[70] Qin W, Carlson LT, Armbrust EV et al. Confounding effects of oxygen and temperature on the $\mathrm{TEX}_{86}$ signature of marine Thaumarchaeota. PNAS, 2015, 112(35) : 10979-10984. DOI: 10.1073/pnas.1501568112.

[71] Hurley SJ, Elling FJ, Könneke M et al. Influence of ammonia oxidation rate on thaumarchaeal lipid composition and the $\mathrm{TEX}_{86}$ temperature proxy. PNAS, 2016, 113(28) : 7762-7767. DOI: 10.1073/pnas.1518534113.

[72] Hurley SJ, Lipp JS, Close HG et al. Distribution and export of isoprenoid tetraether lipids in suspended particulate matter from the water column of the Western Atlantic Ocean. Organic Geochemistry, 2018, 116: 90-102. 